\title{
MATERNAL NEST-BUILDING PERFORMANCE AND FETAL NUMBER IN ROCKLAND-SWISS ALBINO MICE
}

\author{
RONALD GANDELMAN
}

Department of Psychology, Rutgers University, New Brunswick, New Fersey 08903, U.S.A.

(Received 9th January 1975)

\begin{abstract}
Summary. A significant correlation was shown in Rockland-Swiss albino mice between the number of fetuses and maternal nest-building performance as assessed by the amount of nesting material gathered into the cage. The greater the number of fetuses, the more nesting material was gathered. A significant correlation first appeared on Day 4 and was maintained until Day 18 of gestation.
\end{abstract}

Mice construct one of two types of nests depending upon their reproductive state. Non-pregnant female and male mice build small saucer-shaped nests that have been referred to as 'sleeping nests'; pregnant mice construct large enclosed nests called 'maternal' or 'brood nests' because it is within these nests that the young subsequently are maintained (Koller, 1952, 1956).

Progesterone is apparently responsible for eliciting the building of brood nests. Plasma progesterone levels in mice normally are high throughout most of the gestation period and decline just before parturition (Murr et al., 1974). Maternal nest-building follows a similar time course. The administration of progesterone to intact non-pregnant mice leads to the construction of nests that are qualitatively and quantitatively similar to those built by pregnant animals (Koller, 1952, 1956; Lisk et al., 1969). It is probable that progesterone must synergize with small amounts of oestrogen in order to produce maximum nest-building because mice with ovaries exhibit greater amounts of nest-building in response to progesterone administration than do mice without ovaries (Lisk et al., 1969), and large amounts of oestrogen can block progesterone-induced nest-building (Lisk, 1971). Gonadectomized males are unresponsive to progesterone and oestrogen treatment unless gonadectomy is performed at birth (Lisk et al., 1973). Gonadectomized females injected with testosterone propionate at birth fail to show nest-building in response to progesterone and oestrogen treatment. These findings, and the fact that the simultaneous administration of oestrogen and testosterone propionate to intact females does not induce nest-building, indicate that nest-building is sexually dimorphic as a result of the presence of androgen (Gandelman, 1973).

While observing maternal nest-building of mice, it became apparent that large differences existed between animals with respect to nest-building per- 
formance, i.e. some pregnant mice consistently built larger nests than did others. Those animals that constructed larger nests subsequently gave birth to more young than did those that built smaller maternal nests. The results of the following experiment support the initial observation by showing a significant positive correlation between the amount of maternal nest-building and number of fetuses.

Virgin Rockland-Swiss albino mice (R-S) from a closed colony maintained as an outbred strain were housed in groups at 60 to 70 days of age with adult R-S males. The females were examined each morning for the presence of copulatory plugs and when one was discovered (Day 1) the female was housed individually in a $28 \times 18 \times 13 \mathrm{~cm}$ cage, the floor of which was covered with wood shavings. The animals were provided with excess food and water and were kept on a $12 \mathrm{hr}$ light/12 hr dark cycle with the lights on between 06.00 and 18.00 hours. A total of 20 mice whose conceptions were known were used.

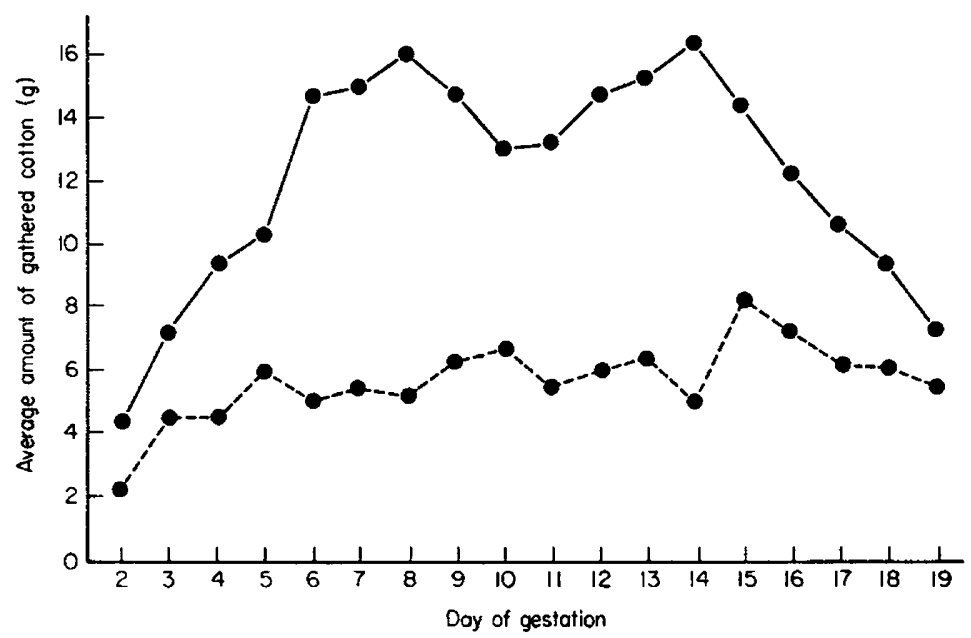

TExT-FIG. 1. The average amount of nesting material (cotton) gathered daily into the cages by individually housed pregnant $(-)$ and virgin $(\ldots-)$ female mice. The data for the virgin females were obtained from Zarrow et al. (1971).

Nest-building was assessed by recording the amount of nesting material gathered into the cage. This was accomplished by placing a pre-weighed quantity of absorbent cotton into a receptacle on the top of the cage of each individually housed animal. Between 08.00 and 09.00 hours the following morning, the cotton pulled by the mouse from the receptacle into the cage was removed and discarded and the cotton remaining in the receptacle was weighed and replenished. This procedure was performed daily from Day 2 until Day 19 of pregnancy. Since most if not all of the material is incorporated into the nest (Zarrow et al., 1971), the amount of nesting material gathered is a reliable indicator of nest size. Mice are not affected by the daily removal of the nests and will build new nests, but the procedure causes an increase in total nestbuilding activity since the initial nest is usually just enlarged. Immediately 
after the weighing of nesting material on Day 19, the animals were killed with ether and the number of fetuses was recorded.

Text-figure 1 depicts the average amount of nesting material gathered daily by pregnant mice. Nest-building increased by the 3rd, peaked by the 5 th, and began to decline by the 16th day of pregnancy while virgin mice constructed only small nests throughout a comparable testing period.

The total amount of nesting material gathered by each animal until Day 19 of gestation plotted against the number of fetuses is shown in Text-fig. 2. It is apparent that a relationship exists between nest-building performance and the number of fetuses; the greater the number of fetuses the greater the amount of nest-building (Pearson Product Moment correlation $=+0.57$, d.f. $=18$, $P<0.02)$. The average litter size of 10.7 young was similar to that found in our colony of R-S mice.

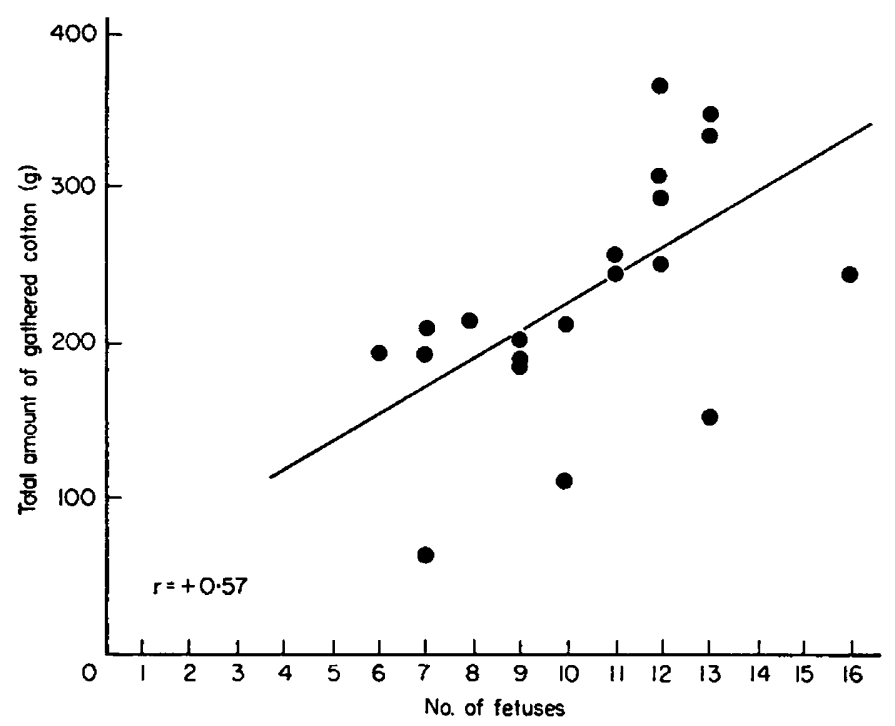

Text-Fig. 2. A scatter plot and regression line for the relationship between the total amount of gathered cotton and the number of fetuses in mice. The regression equation for the best-fitting line was $y=+16 \cdot 81 x+54 \cdot 9$.

To determine when during gestation a significant correlation first appeared and for how long it persisted, correlations between the number of fetuses and the amount of gathered nesting material were computed for each day of the testing period. A significant correlation first appeared on Day 4 of gestation $(r=$ +0.70 , d.f. $=18, P<0.01$ ) and was maintained until Day 18 of pregnancy.

Since progesterone is the putative mediator of maternal nest-building in the mouse, the basis for the relationship between the number of fetuses and nestbuilding performance as assessed by the amount of gathered nesting material may reside in a mechanism that can affect the secretion of progesterone. It has been established that placental tissue secretes a substance having luteotrophic properties. Perhaps, when the absolute amount of placental tissue increases (i.e. when the number of fetuses is greater), the amount of luteotrophic stimula- 
tion is greater, thus resulting in an elevated secretion of progesterone and greater amounts of nest-building. To my knowledge, plasma progesterone levels in mice have not been measured and compared with the number of fetuses. Such a relationship apparently does not obtain in the rabbit since plasma progesterone levels in normal animals and those induced to superovulate did not differ, although the latter produced significantly more fetuses (Pollidoro \& Black, 1970).

This research was supported by funds from the Biomedical Science Support Grant from the United States Public Health Service, by Grant 07-2126 from the Research Council of Rutgers University, and by Grant HD-06863 from the National Institutes of Child Health and Human Development, The National Institute of Health.

\section{REFERENCES}

Koller, G. (1952) Der Nestbau der weissen Maus und seine hormonale Auslosung. Zool. Anz., Suppl. $17,160-168$.

Koller, G. (1956) Hormonale und psychische Steuerung beim Nestbau weissen Mause. Zool. Anz., Suppl. 19, 123-132.

Lisk, R.D. (1971) Oestrogen and progesterone synergism and elicitation of maternal nest-building in the mouse. Anim. Behav. 19, 606-610.

Lisk, R.D., Pretlow, R.A. \& Friedman, S.M. (1969) Hormonal stimulation necessary for elicitation of maternal nest-building in the mouse (Mus musculus). Anim. Behav. 17, 730-737.

Lisk, R.D., Russel, J.A., Kahler, S.G. \& HANKs, J.B. (1973) Regulation of hormonally mediated maternal nest structure in the mouse (Mus musculus) as a function of neonatal hormone manipulation. Anim. Behav. 21, 296-301.

MurR, S.M., Stabenfeldt, G.H., Bradford, G.E. \& Geschwind, I.I. (1974) Plasma progesterone during pregnancy in the mouse. Endocrinology 94, 1209-1211.

Pollidoro, J.P. \& Black, D.L. (1970) Peripheral progesterone and the number of foetuses in normal and superovulated rabbits. F. Reprod. Fert. 22, 493-496.

Zarrow, M.X., Gandelman, R. \& Denenberg, V.H. (1971) Lack of nest building and maternal behavior in the mouse following olfactory bulb removal. Horm. \& Behav. 2, 227-238. 